\title{
Pré-enriquecimento e isolamento direto para identificação de Campylobacter em swabs cloacais e carcaças de frango*
}

\author{
Pre enrichment and direct plating in the identification of Campylobacter in cloacae swabs and broiler \\ carcasses \\ Suzete Lora Kuana', Luciana Ruschel dos Santos' ${ }^{2}$, Laura Beatriz Rodrigues', Anderlise Borsoi', Aline \\ Kellermann', Carlos Tadeu Pippi Salle', Hamilton Luiz de Souza Moraes' \& Vladimir Pinheiro do \\ Nascimento'
}

\section{RESUMO}

Campylobacter são microorganismos patogênicos associados com aves ou alimentos de origem avícola e sua importância está relacionada à alta prevalência de Campylobacter nos frangos de corte e suas carcaças, correlacionados com gastroenterite em humanos. Neste estudo, monitorou-se 22 lotes de frango de corte com idades entre 3 a 5 semanas na granja e 35 dias no abate e avaliou-se os métodos de pré-enriquecimento (PE) e isolamento direto (ID) para identificação de Campylobacter em swabs cloacais e carcaças de frango. Realizaram-se 22 análises de swabs cloacais pelo PE e pelo ID, 96 análises de carcaças pelo ID e, destas, 95 pelo PE. Para o isolamento direto a partir de swabs utilizou-se o ágar mCCDA acrescido de suplemento seletivo, acondicionado em embalagem não permeável e microaerofilia com mistura de gases $\left(5 \% \mathrm{O}_{2}\right.$, $10 \% \mathrm{CO}_{2}$ e $85 \% \mathrm{~N}_{2}$ ). Para o PE, os swabs foram inoculados em pool no caldo Bolton suplementado com antibióticos e $200 \mathrm{mg} /$ L de TTC, seguido de inoculação em ágar mCCDA, também em microaerofilia. As carcaças também foram analisadas para ambos os métodos, utilizando-se caldo Bolton no pré-enriquecimento, seguido de inoculação em mCCDA ou isolamento direto em ágar Bolton com TTC, sempre em microaerofilia. Não houve diferença significativa $(p=1,00)$ entre os métodos de pré-enriquecimento e isolamento direto nas amostras de swabs e carcaças. Identificou-se 81,8\% lotes positivos por ID e 77,3\% pelo PE na análise dos swabs e 99,0\% das carcaças pelo PE e 97,9\% pelo ID. Os métodos de pré-enriquecimento e isolamento direto foram homogêneos e sensíveis para deteç̧ão de Campylobacter em amostras de swabs cloacais e carcaças de frango. Entretanto, pela praticidade e antecipação dos resultados em 24 horas, recomenda-se a utilização do método de isolamento direto.

Descritores: Campylobacter, pré-enriquecimento, isolamento direto, swabs cloacais, carcaças de frangos.

\section{ABSTRACT}

Campylobacter are pathogenic microorganisms associated with poultry or poultry products. Its importance is related to high prevalence of Campylobacter in broiler flocks and in carcasses, which frequency is correlated to gastroenteritis in human. This study was realized in 22 broiler chicken flocks with from 3 to 5 weeks and the slaughter age of 35 days. Were evaluated the pre-enrichment (PE) and direct plating (DP) in the identification of Campylobacter in cloacae swabs and broiler carcasses. Were analyzed 22 cloacae swabs by PE and DP, 96 carcasses by DP, and of these, 95 by PE. In the DP, the swabs were plated directly onto selective modified agar (mCCDA) and placed in waterproof bags, under microaerophilia, with a gas mixture $\left(5 \% \mathrm{O}_{2}, 10 \% \mathrm{CO}_{2}\right.$ and $85 \% \mathrm{~N}_{2}$ ). In the PE, they were pooled onto Bolton broth supplemented with antibiotics, $15 \mathrm{~g} /$ L of agar, $0.5 \mathrm{~g} / \mathrm{L}$ of iron sulfate and $200 \mathrm{mg} / \mathrm{L}$ of TTC, followed by plating onto mCCDA, also under microaerophilia. Carcasses were assessed in both methods using Bolton broth in PE, followed by plating onto mCCDA, and DP onto Bolton agar with TTC. No statistically significant difference $(\mathrm{p}=1.00)$ was observed in swabs and carcasses samples between PE and DP methods. The flocks yielded positive for DP and PE 81.8\% (18/22) and 77.3\% (17/22) of cases, respectively. In broiler carcasses was noted rates of 99.0\% (95/96) for PE and 97.9\% (94/96) for DP. The pre-enrichment and direct plating methods were homogeneous and sensitive for the detection of viable cells of Campylobacter isolates obtained from cloacae swabs and broiler carcasses. However, direct plating should be recommended, due to its practical usefulness and to the possibility of having the results within 24 hours.

Key words: Campylobacter, pre-enrichment, direct plating, cloacae swabs, broiler carcasses.

*Trabalho originado da Dissertação de Mestrado do primeiro autor. Programa de Pós-graduação em Ciências Veterinárias (PGCV-UFRGS). ${ }^{1}$ Centro de Diagnóstico e Pesquisa em Patologia Aviária (CDPA), Faculdade de Veterinária, Universidade Federal do Rio Grande do Sul (UFRGS), Porto Alegre, RS/Brasil. ${ }^{2}$ Faculdade de Agronomia e Medicina Veterinária. Universidade de Passo Fundo (FAMV), Universidade de Passo Fundo (UPF), Passo Fundo, RS. CORRESPONDÊNCIA: L.R. Santos [luruschel@upf.br; Fax: (54) 3316 8485]. 


\section{INTRODUÇÃO}

Bactérias do gênero Campylobacter são reconhecidas como causa comum de gastroenterite em humanos e os produtos de origem animal, especialmente avícolas, são considerados o principal veículo para infecções humanas. O trato intestinal das aves domésticas é um reservatório de Campylobacter [11] e as carcaças e vísceras comestíveis podem se contaminar durante o abate, carreando, assim, o agente para produtos acabados e prontos para consumo [3].

Por ser um microorganismo microaerófilo, o Campylobacter é considerado de difícil cultivo, além da inexistência de metodologias padronizadas e intervenções estratégicas específicas para a redução da contaminação das carcaças de frango pelo agente. Entretanto, o uso de suplementos $(0,025 \%$ de sulfato de ferro, metabissulfito de sódio e piruvato de sódio) possibilitam maior tolerância ao oxigênio, sem a necessidade do acréscimo de sangue, por reduzir os componentes tóxicos derivados do oxigênio, como peróxido de hidrogênio, oxigênio simples e íons superóxidos [16]. Além disto, o incremento dos meios de cultura com a adição de antibióticos suprime a microbiota fecal competidora e favorece o crescimento de campilobacters em colônias facilmente detectáveis. Adicionalmente, diferentes métodos de isolamento têm sido relatados, incluindo ou não passos de pré enriquecimento seletivo, seguidos de inoculação em ágares seletivos [9].

Assim, o objetivo deste trabalho foi avaliar os métodos de pré-enriquecimento (PE) e isolamento direto (ID) para identificação de Campylobacter em swabs cloacais e carcaças de frango.

\section{MATERIAIS E MÉTODOS}

O trabalho foi realizado em 22 aviários de uma agroindústria do sul do Brasil, entre outubro e novembro de 2002. A escolha das granjas foi ao acaso e intencional para aves a partir das três semanas de idade, uma vez que há uma incidência maior e de forma crescente até o abate para a colonização por Campylobacter [13]. Foram realizadas 22 análises de swabs cloacais pelos métodos de pré-enriquecimento e de isolamento direto (ID), (onde uma amostra positiva caracterizou o lote como positivo), 96 carcaças pelo isolamento direto e destas, 95 pelo pré-enriquecimento. Os swabs foram introduzidos na cloaca e o material fecal imediatamente colocado em meio de transporte Cary Blair Medium (CM

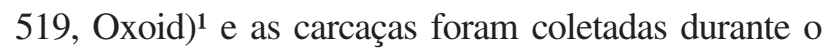

abate, previamente marcadas com um lacre após a escalda e retirada das penas.

\section{Processamento microbiológico de pré-enriquecimento}

Os swabs cloacais foram inoculadas em pool em $60 \mathrm{~mL}$ de caldo de enriquecimento seletivo Bolton (CM983, Oxoid) ${ }^{1}$, com suplemento seletivo contendo cefoperazona, trimetoprim, vancomicina e cicloheximida (SR183E, Oxoid) ${ }^{1}$. O ar foi removido dentro do frasco, de forma a criar um fluxo de uma mistura de $5 \% \mathrm{O}_{2}$, $10 \% \mathrm{CO}_{2}$ e $85 \% \mathrm{~N}_{2}$, estabelecendo assim a microaerofilia e as amostras incubadas por 24 horas a $42^{\circ} \mathrm{C}$. Subseqüentemente, 1 ì foi estriado em ágar mCCDA (CM739, Oxoid) ${ }^{1}$, com suplemento seletivo (SR155, Oxoid) ${ }^{1}$ e incubado por $48 \mathrm{~h}$ em microaerofilia $\left(5 \% \mathrm{O}_{2}, 10 \% \mathrm{CO}_{2}\right.$ e $85 \% \mathrm{~N}_{2}$ ). As colônias suspeitas foram identificadas presuntivamente e confirmadas pelo teste de aglutinação em látex.

As carcaças foram rinsadas em $150 \mathrm{~mL}$ de água peptonada tamponada $1 \%$ (AP $1 \%$ ) e agitadas manualmente por 2 minutos. Transferiu-se $10 \mathrm{~mL}$ para frascos contendo $90 \mathrm{~mL}$ de caldo de enriquecimento seletivo Bolton (CM983, Oxoid) ${ }^{1}$, adicionado de suplemento seletivo contendo cefoperazona, trimetoprim, vancomicina e cicloheximida (SR183E, Oxoid) ${ }^{1}$. O ar foi removido de dentro do frasco, de forma a criar um fluxo com uma mistura de $5 \% \mathrm{O}_{2}, 10 \% \mathrm{CO}_{2}, 85 \% \mathrm{~N}_{2} \mathrm{e}$ as amostras incubadas por 24 horas a $42^{\circ} \mathrm{C}$. Subsequientemente, $1 \mathrm{iL}$ foi estriado em ágar mCCDA (CM739, Oxoid) ${ }^{1}$, com suplemento seletivo (SR155, Oxoid) ${ }^{1}$, incubados em microaerofilia $\left(5 \% \mathrm{O}_{2}, 10 \% \mathrm{CO}_{2}\right.$ e $\left.85 \% \mathrm{~N}_{2}\right)$ por $48 \mathrm{~h}$. As colônias suspeitas foram identificadas presuntivamente e confirmadas pelo teste de aglutinação em látex.

\section{Processamento microbiológico de isolamento direto}

Foi procedida a cultura das amostras de swabs de cloaca conforme o método de isolamento direto, identificação presuntiva e teste de aglutinação em látex. O isolamento direto foi realizado a partir da rinsagem das carcaças com $150 \mathrm{~mL}$ em AP $1 \%$, conforme descrito no método de pré-enriquecimento. Foram transferidas alíquotas de $0,1 \mathrm{~mL}$ e espalhadas com a alça de Drigalsky em placas de meio seletivo. Foi utilizado como meio seletivo o caldo de enriquecimento seletivo Bolton (CM983, Oxoid) ${ }^{1}$ sem sangue lisado de cavalo e suplementado com antibióticos (SR183E, Oxoid) ${ }^{1}, 15 \mathrm{~g} / \mathrm{L}$ de ágar, $0,5 \mathrm{~g} / \mathrm{L}$ de sulfato de ferro e $200 \mathrm{mg} / \mathrm{L}$ de TTC, este último para facilitar a identificação das colônias [10]. As placas foram incubadas em microaerofilia $\left(5 \% \mathrm{O}_{2}\right.$, $10 \% \mathrm{CO}_{2}$, e $85 \% \mathrm{~N}_{2}$ ) por $48 \mathrm{~h}$ e as colônias submetidas 
à identificação presuntiva de Campylobacter e confirmadas por aglutinação em látex.

Para análise estatística utilizou-se a comparação das frequiências marginais pelo teste de McNemar $(p<0,05)$ e os resultados foram avaliados com auxílio do programa estatístico Statistical Package for the Social Sciences e do programa BRAILE, D.M. \& GODOI, M.F. para o teste de acurácia.

\section{RESULTADOS}

Os resultados do isolamento de Campylobacter em swabs cloacais utilizando os métodos de préenriquecimento (PE) e isolamento direto (ID) são apresentados na Tabela 1. Os resultados do isolamento de Campylobacter em carcaças de frango utilizando os métodos de pré-enriquecimento e isolamento direto são apresentados na Tabela 2.

Tabela 1. Isolamento de Campylobacter em swabs cloacais utilizando os métodos de pré-enriquecimento (PE) e isolamento direto (ID)*

\begin{tabular}{|l|c|c|c|}
\hline Método & $\begin{array}{c}\text { Isolamento } \\
\text { direto } \\
\text { positivo }\end{array}$ & $\begin{array}{c}\text { Isolamento } \\
\text { direto } \\
\text { negativo }\end{array}$ & Total \\
\hline Pré-enriquecimento positivo & $17 / 22(77,3 \%)$ & $0 / 22(0,0 \%)$ & $17 / 22(77,3 \%)$ \\
\hline Pré-enriquecimento negativo & $1 / 22(4,5 \%)$ & $4 / 22(18,2 \%)$ & $5 / 22(22,7 \%)$ \\
\hline Total & $18 / 22(81,8 \%)$ & $4 / 22(18,2 \%)$ & $22 / 22(100 \%)$ \\
\hline
\end{tabular}

*Teste exato de McNemar $(P=1,00 ; \mathrm{gl}=1)$

Tabela 2. Isolamento de Campylobacter em carcaças de frangos utilizando os métodos de pré-enriquecimento (PE) e isolamento direto (ID)*

\begin{tabular}{|l|c|c|c|}
\hline Método & $\begin{array}{c}\text { Isolamento } \\
\text { direto } \\
\text { positivo }\end{array}$ & $\begin{array}{c}\text { Isolamento } \\
\text { direto } \\
\text { negativo }\end{array}$ & Total \\
\hline Pré-enriquecimento positivo & $93 / 95(96,9 \%)$ & $2 / 95(2,1 \%)$ & $95(99 \%)$ \\
\hline Pré-enriquecimento negativo & $1 / 95(1,0 \%)$ & $0 / 95(0,0 \%)$ & $1(1 \%)$ \\
\hline Total & $94(97,9 \%)$ & $2 / 95(2,1 \%)$ & $96(100 \%)$ \\
\hline
\end{tabular}

*Teste exato de $\operatorname{McNemar}(P=1,00 ; \mathrm{gl}=1)$

\section{DISCUSSÃO}

Não houve diferença significativa $(p=1,00)$ entre os métodos avaliados para isolamento de Campylobacter a partir de swabs cloacais, com identificação de 81,8\% (18/22) de lotes positivos pelo ID e 77,3\% (17/22) pelo PE e em carcaças de frango, com 99,0\% (95/96) pelo PE e 97,9\% (94/96) pelo ID.

Em concordância com o presente trabalho, não foi encontrada diferença significativa entre os procedimentos de pré-enriquecimento no meio de Hunt e posterior inoculação no meio mCCDA e isolamento direto em ágar Cefex (ambos em microaerofilia) para isolamento de Campylobacter em carcaças de frango [9]. Três meios sólidos seletivos (Peterz's Charcoal Cefoperazone Deoxycolate Agar (mCCDA), CampyCefex Agar e Charcoal-based selective Medium) foram testados para isolamento de Campylobacter em carcaças, miúdos (moela e fígado) e cortes de aves e não apresentaram diferenças significativas entre eles, com 76\%, 64\% e $68 \%$ de isolamento, respectivamente. Entretanto, o isolamento de Campylobacter em swabs cloacais demonstrou positividade de $55 \%$ pelo ID e apenas $7 \%$ com o pré-enriquecimento [6].

O método de análise e o plano de amostragem são decisivos para o isolamento de Campylobacter [4,8] e três fatores seriam fundamentais para o isolamento de Campylobacter: o uso de meios seletivos; a incubação em atmosfera com redução de oxigênio e adição de $\mathrm{CO}_{2}$ e a incubação no isolamento primário a $42^{\circ} \mathrm{C}$ [12]. $\mathrm{O}$ cultivo de Campylobacter tem sido realizado nas rotinas laboratoriais pelo incremento dos meios de cultura, nos quais a adição de antibióticos suprime a microbiota fecal competidora e favorece o crescimento da bactéria [15]. 
No presente estudo, a positividade de $99,0 \%$ pelo PE e 97,9\% pelo ID para Campylobacter em carcaças coletadas no abatedouro foi similar aos $98,0 \%$ encontrados nos EUA [14]. Entretanto, foi superior aos 83\% encontrados em carcaças resfriadas adquiridas em supermercados da Grã-Bretanha, sugerindo que os níveis de contaminação podem ter sido reduzidos pelo tempo de exposição em condições aeróbicas [8]. Entre 30 e $100 \%$ das aves abrigam o Campylobacter no intestino [1] e a bactéria foi detectada em fezes de frango em $83 \%, 86,8 \%$ e $90 \%$ das amostras examinadas, respectivamente $[2,5,7]$.

A contaminação das carcaças é dependente da idade e do nível da contaminação dos lotes na granja e da influência de variáveis relativas à pro dução, transporte e processo. A determinação do nível de contaminação nas carcaças por Campylobacter teria implicações mais severas na exposição para o consumidor do que a simples freqüência com níveis baixos, sendo fundamental a padronização das metodologias para a pesquisa de Campylobacter, paralelamente a um esclarecimento epidemiológico para uma melhor rastreabilidade, tanto para aves vivas como para carcaças de frango e seus produtos [10].

\section{CONCLUSÃO}

A acurácia entre os métodos de pré-enriquecimento e isolamento direto foi de $96,9 \%$, indicando que os dois métodos podem ser utilizados para a identificação de Campylobacter. Entretanto, devido à antecipação dos resultados em 24 horas, recomenda-se adotar o método de isolamento direto.

${ }^{1}$ Oxoid, Cambridge, England.

\section{NOTAS INFORMATIVAS}

\section{REFERÊNCIAS}

1 Berrang M.E., Smith D.P. \& Windham W.R. 2004. Effect of intestinal content contamination on broiler carcass Campylobacter counts. Journal of Food Protection. 67: 235-238.

2 Blaser M.J., LaForce F.M., Wilson N.A. \& Wang W.L. 1980. Reservoirs for human campylobacteriosis. Journal of Infectious Diseases. 141: 665-669.

3 Carvalho A.C.F.B., Lima V.H.C., Pereira G.T. \& Schocken-Iturrino R.P. 2001 Campylobacter em granja avícola. Revista Portuguesa de Ciências Veterinárias. 96: 191-195.

4 Domíngues C., Gómez I. \& Zumalacárregui J. 2002. Prevalence of Salmonella and Campylobacter in retail chicken meat in Spain. International Journal of Food Microbiology. 72: 165-168.

5 Grant I.H., Richardson N.J. \& Bokenheuser V.D. 1980. Broiler chickens as potential source of Campylobacter infections in humans. Journal of Clinical Microbiology. 11: 508-510.

6 Hald B., Wedderkopp A. \& Madsen M. 2000. Thermophilic Campylobacter spp. in Danish broiler production: a crosssectional survey and a retrospective analysis of risk factors for occurrence in broiler flocks. Avian Pathology. 29: 123-131.

7 Jaramilo H.F. 1983. Espécies termofílicas de Campylobacter: aspectos bacteriológicos, epidemiológicos e patogênicos. 114p. São Paulo, SP. Tese de Doutorado. Escola Paulista de Medicina, São Paulo.

8 Joergensen F., Bailey R., Williams S. \& Henderson P. 2002. Prevalence and numbers of Salmonella and Campylobacter spp. on raw, whole chickens in relation to sampling methods. International Journal of Food Microbiology. 76: 151-164.

9 Line J.E., Stern N.J., Lattuada C.P. \& Benson S.T. 2001. Comparison of methods for recovery and enumeration of Campylobacter from freshly processed broilers. Journal of Food Protection. 64: 982-986.

10 Line J.E. 2001. Development of a selective differential agar for isolation and enumeration of Campylobacter spp. Journal of Food Protection. 64: 1711-1715.

11 Mead G.C. 2002. Factors affecting intestinal colonisation of poultry by Campylobacter and role of microflora in control. World's Poultry Science Journal. 58: 169-178.

12 Shih D.Y.C. 2000. Isolation and identification of enteropathogenic Campylobacter spp. from chicken in Taipei. Journal of Food Protection. 63: 304-308.

13 Stern N.J. 1995. Influence of season and refrigerated storage on Campylobacter spp. contamination of broiler carcasses. Journal Applied Poultry Research Savoy. 4: 235-238.

14 Stern N.J. \& Robach M.C. 2003. Enumeration of Campylobacter spp. in broiler feces and in corresponding carcasses. Journal of Food Protection. 66: 1557-1563.

15 Uyttendaele M. \& Debevere J. 1996. Evaluation of Preston medium for detection of Campylobacter jejuni in vitro and in artificially and naturally contaminated poultry products. Food Microbiology. 13: 115-122.

16 Wonglumsom W., Vishnubhatla A., Kim J.M. \& Fung D.Y.C. 2001. Enrichment media for isolation of Campylobacter jejuni from inoculated ground beef and chicken skin under normal atmosphere. Journal of Food Protection. 64: 630-634. 